\title{
Determination methodology of the subsidence speed of small-dispersed particles of different ranges of storage facilities by visual recording
}

\author{
Valeriy Azarov ${ }^{1}$, Daniil Dobrinskiy ${ }^{1}$, Vladislav Lupinogin ${ }^{1,{ }^{*}}$ and Anastasia Sakharova ${ }^{1 . \dagger}$, \\ ${ }^{1}$ Institute of Architecture and Civil Engineering of Volgograd State Technical University, 400074, \\ Akademicheskaya st. 1, Volgograd Russia
}

\begin{abstract}
Was researched a small-dispersed dust from storage facilities in differend ranges. Was carried out a comparative analysis of the subsidence speed of the obtained particle sizes. The laboratory installation was upgraded and was installed the automatic sample dumping, and video recorder with the possibility of enlarging the image and manual focusing. Due to implementation of additional elements in the design of the installation, it was possible to exclude mechanical interference and simplify the design of the equipment. At the same time, it was possible to minimize coverage error during the experiment. The main aim was to determine the dispersal composition with a recording on video equipment with subsequent processing of the obtained data.
\end{abstract}

\section{Introduction}

Currently, storage facility is not just a storage room for goods (products, equipment, spare parts), but a basis of logistics for delivery to the final customer. To all this, the storage has become a huge complex with additional, adjacent rooms and areas of technological operations.

There is a classification of storage facilities, a kind of gradation. It is divided according to some points, such as, type of construction, height of ceilings, grid of columns, floor covering, minimum pressure on the floor, floor height from ground level, unloading area, availability of technical and engineering systems and buildings, availability of a separate improved area characteristics, the presence of administrative accommodations.

Standard storage areas reach several tens of thousands of square meters. Accordingly, there is a need for structuring and determination of contamination degree from warehouses.

\footnotetext{
* Corresponding author: vladlupinogin@gmail.com

† Corresponding author: sax.nastya@yandex.ru
} 


\section{Relevance of the issue}

Currently, in a number of countries, including Russia, determined the content in the atmospheric air of particles with the size of not more than $2.5 \mu \mathrm{m}$ (PM2.5) and not more than $10 \mu \mathrm{m}$ (PM10), because dust particles of ultra-dispersal size is the most dangerous, these particles can infiltrate into the human lungs. A system for monitoring and evaluating the concentration and composition of small sized particles in storage facilities is currently absent, which does not allow an objective evaluation of the dust impact on the quality of the working environment and air emissions [1-4].

\section{Direction of tasks}

The aim of the research is to improve the methodology for determination of the subsidence speed of small-dispersed particles on the example of storage facilities.

To achieve the aim, the following tasks were solved: determination of the concentration of small dust fractions from storage facilities (PM10, PM2,5), and also was carried out a study of the aerodynamic characteristics of dust particles of PM10 and PM2,5 dust particles in storages and in the air near storages.

\section{Theoretical part}

For determination of dispersal dust composition with the subsidence method in air environment was used a sedimentometer with a modification (fig.1). As basis the installation [5] was taken, on which, were made equipment modifications. Was installed an automatic dust dumping system (5). Also, the video recording system was implemented (6) with video output on the screen (7) for video calibration. During subsidence in fractions, the analyzed sample of crushed material is collected in the upper part of the column of the dispersion environment [6]. At first, happens the dumping of the heaviest and largest particles of the fraction, which are comprehended the height of the cylinder $\mathrm{H}$ for some time $\tau$, settle at the bottom of the sedimentometer. The speed of subsidence is given by the formula $\omega=\mathrm{H} / \tau$ [6-8]. Dumping of dust particles is used with a device with an installed sliding mechanism, and under the influence of gravity dust particles are settled in a fixed air space. Moving with different speed, the particles are settled on the surface (glass), that located in the lower part.

\section{Selection and Evaluation Technique}

Before the experiment was carried out, samples of three different size particle ranges were screened and prepared: 1 - 40-60 $\mu \mathrm{m} ; 2$ - 60-80 $\mu \mathrm{m} ; 3$ - 80-100 $\mu \mathrm{m}$. Each sample was divided into several samples of the same weight of $5 \mathrm{mg}$. After that, each sample was loaded into the device with automatic start and with the installed sliding mechanism for dust dumping. For improvement of visibility of particles during recording process - the surface was highlighted with LED insertions, and additionally for calibration, on the surface of subsidence was applied a "standard" of $1 \mathrm{~mm} 2(1000 \mu \mathrm{m})$ for a comparative analysis of the settling particles. For precisely determination of the start of the video recording, on the video recorder was installed a reset indicator. This indicator is a light 
bulb, that, at given moment lights up simultaneously with the launch of the sliding mechanism.

For each sample is obtained an edited video from the beginning of the subsidence and to the last settled particle. After this, a storyboard of the obtained video is made. The storyboard is a set of images (frames) from the beginning and to the last settled particle. For each sample, the number of images may differ. The next step was image processing (fig. 2). The images were edited in brightness, contrast, and brought into a binary view (white background and particles of the black color). All this with the analogy of the microscopic method, but without its usage. The final step was to load all the processed images into a special program on Python with the use of open libraries, developed for this experiment and the number of black pixels in each image was calculated and presented in tabular form (table 1).

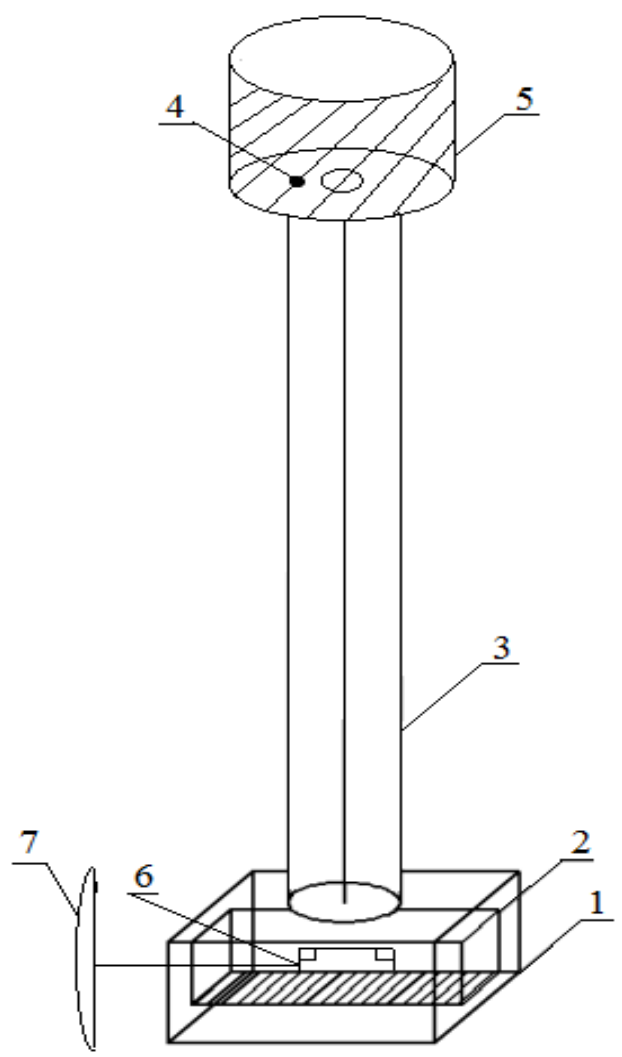

Fig. 1. Modified experimental setup: 1 - base; 2 - the surface of particle subsidence (glass); 3 sedimentation cylinder with the height $\mathrm{H}=2 \mathrm{~m}$, diameter $\mathrm{d}=16 \mathrm{~cm} ; 4$ - LED; 5 - automatic dusting device; 6 - video recorder to record the moment of falling particles; 7 - screen for communication and calibration of video recorder 

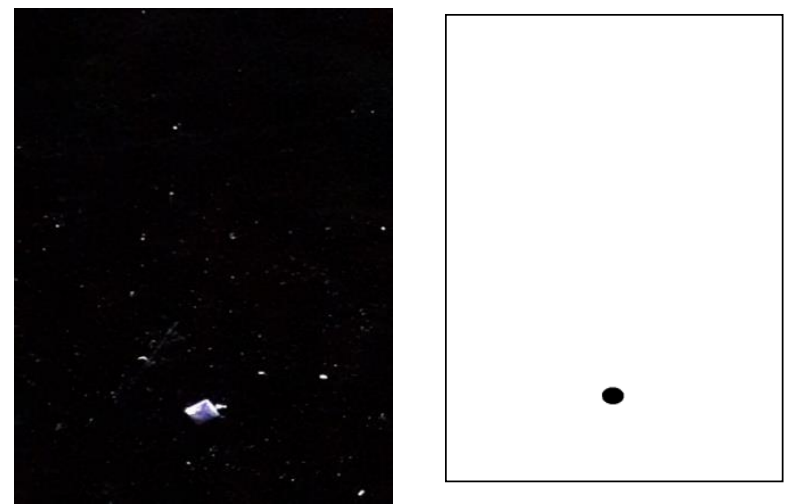

Fig. 2. Image of calibration "standard" before (on the left) and after (on the right) processing.

Table 1. Number of pixels with different ranges of small-dispersed particles

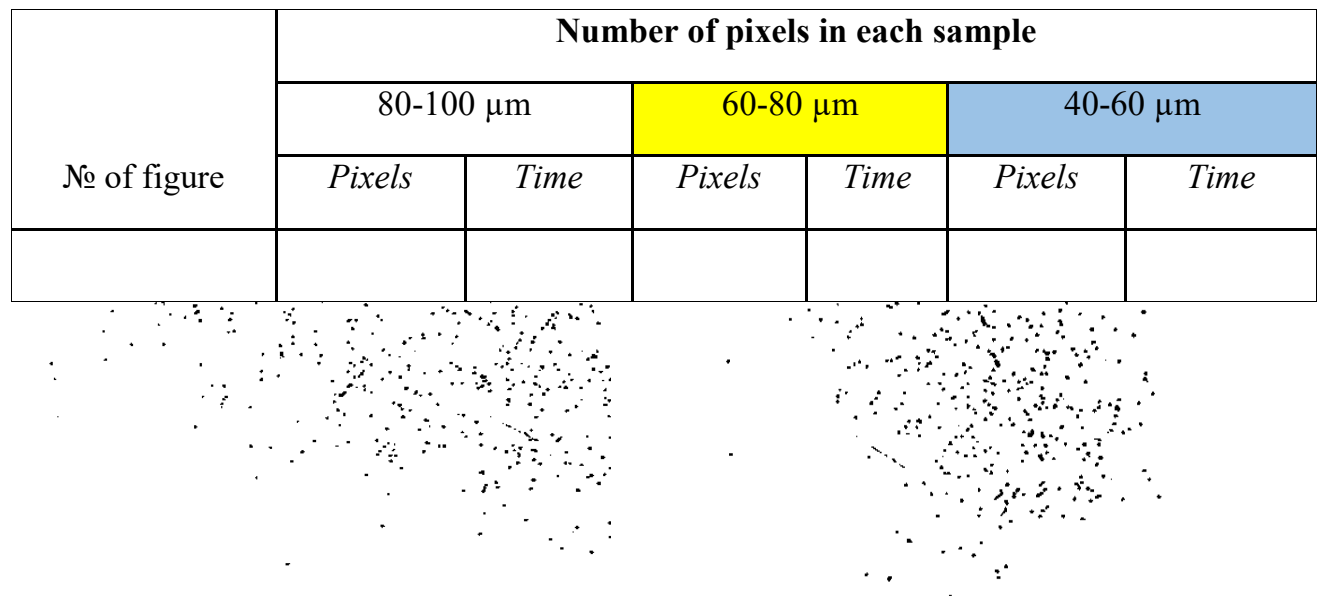

a

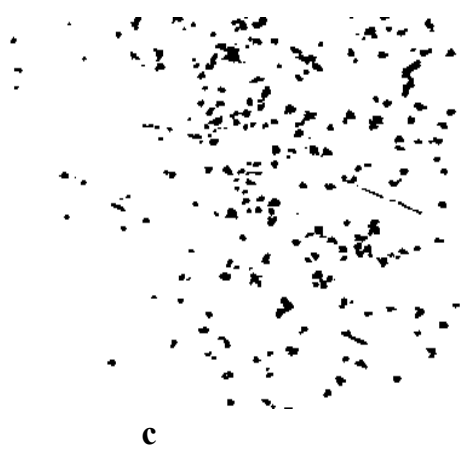

Fig. 3. The image of settled dust particles fractions of different ranges: $a-40-60 \mu \mathrm{m} ; \mathrm{b}-60-80 \mu \mathrm{m} ; \mathrm{c}$ $-80-100 \mu \mathrm{m}$ 


\section{Experimental Results}

Since the frame rate of the video recording is 30 frames/sec, each frame concludes information about the amount of dust on the surface in a time interval of 0,033 s. Acquired data is converted into an overall graph (fig. 4) for each of the ranges. Built integral curves of pixels dependence on the time of subsidence [9-11].

After analyzing the graph on Figure 4, it is possible to calculate the subsidence speed of particles, that fell at the beginning, based on data about the time interval between the sample dumping and the start of video recording of particles. On Figure 4 represented the entire time period of subsidence. For a more detailed analysis was highlighted a period of the beginning of the fall of the first particles $(4,33-6,67 \mathrm{~s})$, and submitted on a separate graph (fig. 5). According to the graph, on Figure 5 can be seen the start time of the recording of particles subsidence.

Picture analysis on Figure 4 allows to calculate the subsidence rate of particles. All particles of 40-60 $\mu \mathrm{m}$, settled in the time interval (from 5,6 to 19,6 s), consequently, have a subsidence speed in the range (from $0,36-0,1 \mathrm{~m} / \mathrm{s}$ ). Similarly, for particles of $60-80 \mu \mathrm{m}$, the sedimentation rate will vary within (from ${ }_{\tau} 0,42$ to $0,14 \mathrm{~m} / \mathrm{s}$ ). Accordingly, for a particles range of $80-100 \mu \mathrm{m}$, the subsidence speed is within (from 0,47 to $0,18 \mathrm{~m} / \mathrm{s}$ ).

Indirect confirmation of principal correctness of the results is that the following condition being fulfilled: in the research of two monodisperse fractions of the same mass but with different diameters of area ratio, which are occupied by sediment particles is equal to the inverse diameters ratio. For every range, the maximum number of pixels $\left(\mathrm{S}_{\max }\right)$ of the midsection particles is determined. All values of $S_{\tau}$ (current area values) are increasing after 27 seconds and strive to $S_{\max }$. For example, for range of $80-100 \mu \mathrm{m}$ the area of $S_{\max }$ is 90000 pixels, for range of $60-80 \mu \mathrm{m}-60000$ pixels, and for $40-60 \mu \mathrm{m}-50000$ pixels. In fact, graphics of Fig. 4 are integral distribution functions of the dust mass over equivalent diameters of midsection particles. At low doses of dust, the change in the areas of particles subsidence is insignificantly small - no more than $1,5 \%$.

On Fig. 4 the graph section dependence of the pixels number from the subsidence time in the interval from 4 seconds $(0,5 \mathrm{~m} / \mathrm{s})$ to 27 seconds $(0,05 \mathrm{~m} / \mathrm{s})$. The peaks are present on the graph, for example, a peak at 5,33 seconds. The rapid increase of the pixels number and the subsequent recession on the next frame is happening due to the particles rebound effect from the subsidence surface, resulting, that bounced particle goes into the frame. Since its moving speed is quite high, the video camera can't capture it as a stain, and we can observe an elongated plume, that corresponds to the direction of its movement. Since the pixels number from the particle span is bigger than the real number of pixels, which are taken by stain projection, we acquire a rapid increase on the pixels number in some frames. However, after its span and relaxation, the next frame doesn't contain traces of the span, with the result of the lesser pixels number on subsequent frames, than on the frame, where the rebound is recorded, resulting in a peak on the graph. Dependence is approximated and smoothed, and customized to understandable visual view. 


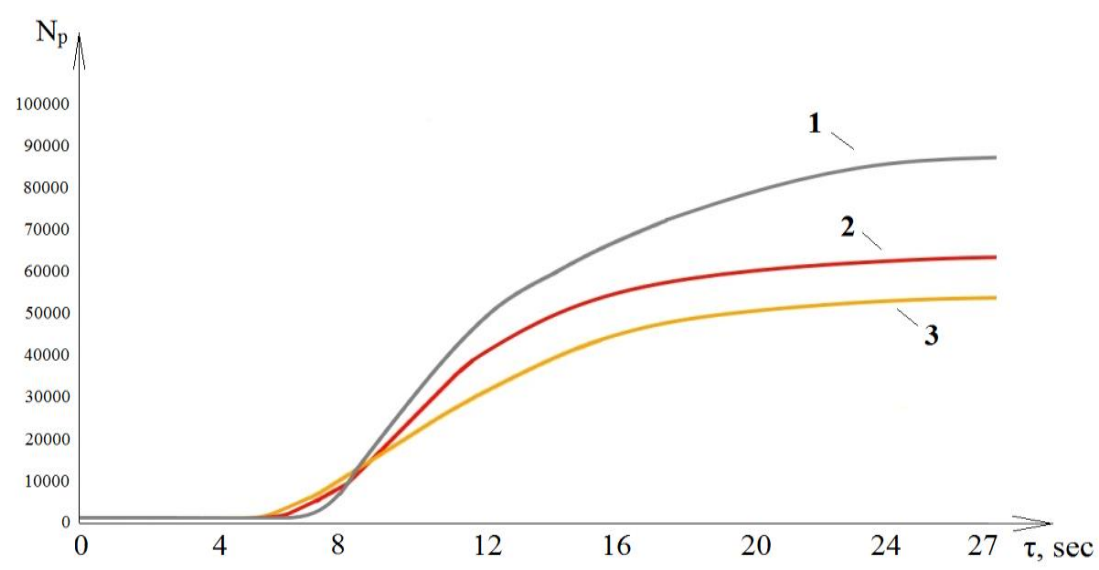

Fig. 4. The dependence of the number of pixels in the total area of the midsections of the settled particles from the subsidence speed for the particles with the size of (with the same mass) from time: 1- 40-60 $\mu \mathrm{m}, 2-60-80 \mu \mathrm{m}, 3-80-100 \mu \mathrm{m}$

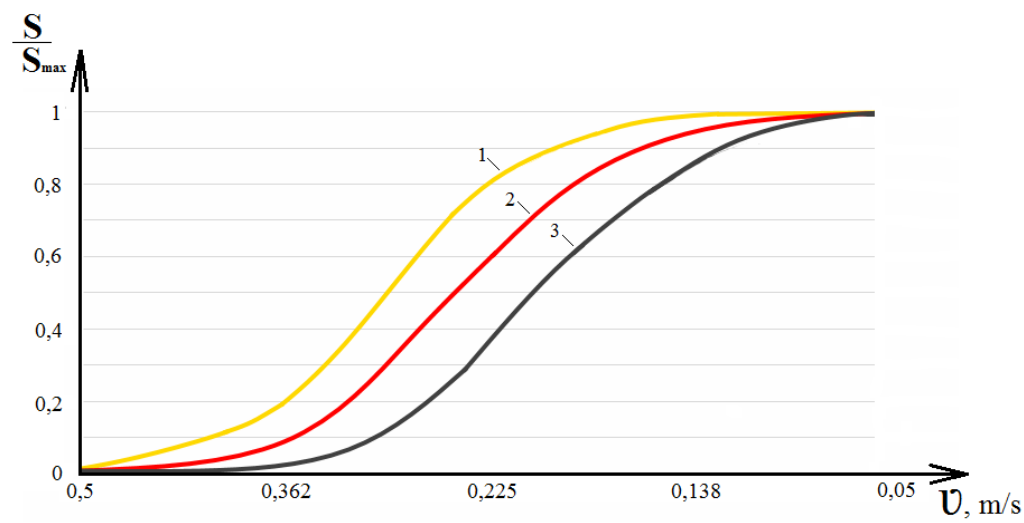

Fig. 5. The dependence of the number of pixels in the total area of the midsections of the settled particles from the subsidence speed for the particles with the size of (with the same mass): 1- 80-100 $\mu \mathrm{m} 2-60-80 \mu \mathrm{m}, 3-40-60 \mu \mathrm{m}$.

As shows the number of settled particles with a speed less than $0,5 \mathrm{~m} / \mathrm{s}$ for all ranges does not exceed $1,5 \%$ of the sample and the presence of such particles is explained by the formation of larger particles after stuffing.

\section{Summary}

The installation for the study of the aerodynamic characteristics of dust was modernized and the method of dispersal dust analysis was improved.

A program to count the number of pixels on each image was written and a graph of dependence of the number of pixels from the subsidence speed was built. Software calculations allow to build integral and differential functions of the mass particles dependence on the equivalent diameters of the midsection of the particles.

Due to the result of experimental studies, it was determined, that particles with the size of 40-60 $\mu \mathrm{m}$ - subsidence speed is within $0,36-0,1 \mathrm{~m} / \mathrm{s}$ and standard speed $0,23 \mathrm{~m} / \mathrm{s}$; 
particles with the size of $60-80 \mu \mathrm{m}$ - have a subsidence speed is within $0,42-0,14 \mathrm{~m} / \mathrm{s}$ and standard $0,28 \mathrm{~m} / \mathrm{s}$; particles with the size of $80-100 \mu \mathrm{m}$ - have a subsidence speed is within $0,47-0,18 \mathrm{~m} / \mathrm{s}$, and standard $0,32 \mathrm{~m} / \mathrm{s}$. It is shown that it is possible to neglect the intersection of particles at low particle doses, when they are thrown into the sedimentation cylinder.

The integral distribution functions of the relative area of the midsections of the particles by the subsidence speed for the same sample of the dumped dust sample are constructed.

Range of changes $\left(\mathrm{S} / \mathrm{S}_{\max }\right)$ from 0 to 1 less in the interval $80-100 \mu \mathrm{m}(90 \mu \mathrm{m})$.

\section{References}

1. V.N. Azarov, O.V. Burlachenko, R.A. Burkhanova, N.A. Marinin, On the study of the aerodynamic characteristics of asbestos cement dust in emissions into the atmosphere, VolgGASU Internet-Bulletin. Ser. : Polythematic, v. 1(20), (2012)

2. V.N. Azarov, S.A. Koshkarev, Improving the environmental safety of the construction industry by improving dust-removal systems using a comprehensive dispersive analysis of dust emissions, Bulletin of the Volgograd State. architectural and construction unthat. Series: Building and Architecture, 43, pp. 161-174 (2016)

3. V.N. Azarov, N.V.Menzelintseva, E.O. Fomina, Experimental studies of the patterns of distribution and sedimentation of cement dust in the air of the working zone of an operator of a cement packaging line,Science and education: architecture, urban planning and construction. Proceedings of the international conference dedicated to the 60th anniversary of the university, Volgograd, pp. 83-87 (2012)

4. V.N. Azarov, N.M. Sergina, T. Kondratenko Problems of protection of urban ambient air pollution from industrial dust emissions, MATEC Web of Conferences, v. 106, (2017). - $\quad$ U URL :https://www.matecconferences.org/articles/matecconf/abs/2017/20/contents/contents.html.

5. A device for determining the dispersed composition of dust Marinin N.A. [and etc.]. Patent for useful model №135806 dated 12/20/2013

6. E.P. Mednikov, Turbulent transfer and sedimentation of aerosols (M.: Science, 1981)

7. P.A. Kouzov, Fundamentals of analysis of the dispersion composition of industrial dusts and crushed materials (L.: Chemistry, Leningr. department, 1987)

8. N. A. Fuchs, Mechanics of aerosols (Moscow: USSR Academy of Sciences, 1955)

9. V.N. Azarov, N.Yu. Karapuzova, S.I. Stefanenko, Analysis of the patterns of sedimentation of dust particles in the working area of the operator of a carousel machine for separating cement packaging, Scientific works of Swold, 5(3), pp. 44-46 (2011)

10. V.N. Azarov, A.I. Evtushenko, V.P. Batmanov, A.B. Strelyaev, V.V. Lupinogin, Aerodynamic Characteristics of Dusting, International Review of Civil Engineering, v. 7(5), pp. 132-136 (2016) -

11. I.V. Stefanenko, K.A. Trokhimchuk, M.V. Trokhimchuk, Urban area of the built-in areas, Applied Mechanics and Materials. The 2nd International Conference Material, v. 875, pp. 183-186 (2018). doi: 10.4028 / www.scientific.net/amm.875.183. 